\title{
Tip 1 Diabetes Mellitus Tanılı Türk Çocuklarında Sınıf I ve Sınıf II HLA Allel Sıklığı
}

\author{
Frequencies of Class I and II HLA Alleles in Turkish Children with \\ Type 1 Diabetes Mellitus \\ - Murat KARAOĞLAN
}

Gaziantep Üniversitesi Tıp Fakültesi, Çocuk Sağlığı ve Hastalıkları Anabilim Dalı, Çocuk Endokrinoloji Bilim Dalı, Gaziantep, Türkiye

\section{ÖZ}

Amaç: Tip 1Diabetes Mellitus (T1DM) bölge, ırk ve etnik kökene göre değişken HLA gen polimorfizmlerinin sorumlu tutulduğu otoimmün bir hastalıktır. Çoğunlukla DR-DQ haplotiplerinin çalışıldığı çok sayıda çalışma bulunmasına karşın, sınıf I HLA-A,B ve C allel iliş̧kisini araştıran daha az rapor bulunmaktadır. Çalışmanın amacı T1DM tanılı Türk çocuklarında sınıf I ve II HLA allel dağılımını araştırmaktır.

Gereç ve Yöntemler: 2017-2019 arası tanı almış 98 (45 kı, 53 erkek) T1DM ve 80 (41 kız, 39 erkek) sağlıklı çocuk HLA A-B-C ve DQ-DR allelleri açısından tarandı. HLA moleküler analizleri PCR yöntemi ile çalıșıldı. DQ, DR için riskli allel ve haplotipler arasındaki farkın ölçülmesinde Ki-kare testi kullanıldı ve her değişken için Odds Ratio (OD) hesaplandı

Bulgular: T1DM'li çocuklarda en sık saptanan DQ2 ( $n=60 ; \% 61.22)$ ve DR3 ( $n=48 ; \% 49)$ 'du. DQ3 \%34.7(n=34), DR4 \%25.5 ( $n=25)$ oranında saptandı. HLA I grubunda en sık saptanan HLA-A2 ( $n=36 ; \% 36.8)$ ve HLA-A3 ( $n=26$;\%26.6)'ti. Diğer HLA lokuslarının sıklığı sırası ile şu şekilde saptandı: HLA-C7 \%25.5 (n=25), HLA-C4 \%20.4 (n=20)HLA-B8 \%18.8 $(n=18)$, HLA-B35 \%15.3 ( $n=15)$. En sı saptanan haplotipler DRB1*03-DQB1*02, DRB1 $04-D Q B 1{ }^{*} 03$ ve DRB1*01DQB1*05'ti. (sırası ile 48(\%49), 19(\%19.3), 11(\%11.2). Kontrol grubu ile karşılaştırıldığında T1DM için en riskli haplotipler DRB1*03-DQB1*02 (OR;11.84) DRB1*01-DQB1*05 (OR;9.98) ve DRB1*04-DQB1*02 (OR;5.15) iken en riskli allel grupları ise DQ2 (OR; 7.44) ve DR3 (OR;6.02) olarak saptandı.

Sonuç: Bu çalışmada T1DM için en riskli HLA allel grupları ve haplotipleri olarak DR3-DQ2 ve DRB1*03-DQB1*02, DRB1*04-DQB1*03, DRB1*01-DQB1*05saptarken HLA-A2/A3, HLA-C7/C4 ve HLA B8/35 allel gruplarının sıklığında artmış bir sıklık saptanmıştır. Bu bulgular, T1DM tanılı Türk çocuklarında HLA sınıf II HLA DR3-DQ2 allel gruplarındaki artmış sıklık olduğunu ve T1DM ile bazı allellerinin artmış sıklığı nedeni ile HLA I sınıfı gen bölgeleri arasındaki ilişkinin de araştırılması gerektiğine işaret etmektedir.

Anahtar Sözcükler: HLA sınıf I-II allel, HLA-DR, HLA DQ, Tip 1 diabetes mellitus

\begin{abstract}
Objective: Type1Diabetes Mellitus (T1DM) is an autoimmune disease in which HLA gene polymorphisms vary according to region, race and ethnicity. Although there are many studies involving mostly DR-DQ haplotypes, there are fewer reports investigating the association of class I HLA-A, B and C alleles. The aim of the study was to investigate the distribution of HLA class I and II alleles in Turkish children with T1DM.

Material and Methods: 98 (45 girls, 53 boys) children with T1DM diagnosed between 2017-2019 and 80 (41 girls, 39 boys) healthy children were screened for HLA A-B-C and DQ-DR alleles. HLA molecular analyzes were performed by PCR method. Chi-square test was used to measure the difference between alleles and DQ-DRhaplotypes. Odds Ratio (OD) was calculated for each variable.

Results: The most common alleles in children with T1DM were DQ2 ( $n=60 ; 61.22 \%)$ and DR3 ( $n=48 ; 49 \%)$. DQ3 and DR4 were $34.7 \%(n=34)$ and $25.5 \%(n=25)$. The most common allelesin the HLA class I were HLA-A2 ( $n=36$; $36.8 \%)$ and HLA-A3 ( $n=26 ; 26.6 \%)$. The frequency of the other alleles were as follows: HLA-C7 25.5\% ( $n=25), H L A-C 4$ 20.4\% ( $n=20)$ HLA-B8 18.8\% ( $n=18)$, HLA-B35 15.3\% ( $n=15)$. The most common haplotypes were DRB1*03-DQB1*02 $(\mathrm{n}=48 ; 49 \%), \mathrm{DRB} 1{ }^{*} 04-\mathrm{DQB1}{ }^{*} 03(\mathrm{n}=19 ; 19.3 \%)$, and DRB1*01-DQB1*05 $(\mathrm{n}=11 ; 11.2 \%)$, respectively. The most risky haplotypes for T1DM were DRB1*03-DQB1 ${ }^{\star} 02(\mathrm{OR}=11.84) \mathrm{DRB} 1{ }^{\star} 01-\mathrm{DQB} 1{ }^{\star} 05(\mathrm{OR}=9.98)$ and $\mathrm{DRB} 1{ }^{\star} 04-\mathrm{DQB} 1{ }^{\star} 02$ $(\mathrm{OR}=5.15)$, while the most risky alleles were $\mathrm{DQ} 2(\mathrm{OR}=7.44)$ and $\mathrm{DR} 3(\mathrm{OR}=6.02)$.
\end{abstract}


Conclusion: In this study, the most risky HLA alleles and haplotypes in Turkish children wtih T1DM were DR3-DQ2 and DRB1*03$\mathrm{DQB} 1{ }^{*} 02, \mathrm{DRB} 1{ }^{*} 04-\mathrm{DQB} 1{ }^{*} 03, \mathrm{DRB} 1{ }^{*} 01-\mathrm{DQB} 1{ }^{*} 05$, and the increased frequencies ofHLA-A2/A3, C7 / C4 and HLA B8 / 35 alleles were found in the HLA class I. These findings suggest that there is an increased frequency of HLA class II HLA DR3-DQ2 allele groups in Turkish children with T1DM, and the relationship between T1DM and HLA I class gene regions should be investigated because of the increased frequency of some HLA-A/B/C alleles.

Key Words: Class I and II HLA alleles, HLA-DR, HLA DQ, Type 1 diabetes mellitus

\section{GiRiş}

Tip 1 Diabetes Mellitus (T1DM), hem genetik hem de çevresel bileşenleri olan otoimmün bir hastalıktır. Genetik duyarlıkta artışa yol açan 6p21 kromozomu üzerinde HLA lokusları üzerinde çok sayıda gen bölgesi tanımlanmıştır (1). Otoimmün süreçlerin yol açtı̆̆ı pankreatik beta hücre yıkımında çoğunlukla sınif II HLA-DRB1 ve HLA-DQB1 lokuslarındaki genler rol oynar (2-3). Bazı araştırmalar sınıf I HLA (A, B, C) genlerinin de hastallkka ile ilișkisini ortaya koymuștur (4-5). Bununla birlikte etnik köken ve bölgelere göre oldukça değişken ve çok sayıda HLA gen polimorfizmi bulunur ve bu genler etyopatogenezi bütünüyle açıklayamazlar (6-7). En yüksek riskli bulunan HLA haplotipler RB1*03:01-DQA1*05:01-DQB1*02:01 (DR3) ve DRB1*04:01/02/04/05/08-DQA1*03:01-DQB1*03:02/04 (DR4) olarak bulunmuştur. Aksine; DRB1*15:01-DQA1*01:02DQB1*06:02 (DR2) haplotiplerinin ise T1DM gelişiminden koruyucu olduğu saptanmıştır (8).

T1DM çocukluk çağının giderek artan sıklıkta görülen çocukluk çağının önemli bir kronik hastalığıdır. Hastalık genetik bir duyarllık temelinde çevresel faktörlerin katkısı ile uzun süreli sessiz otoimmün bir sürecin ardından ortaya çıkmaktadır. Etyopatogeneze ilişkin özgün risk faktörlerinin belirlenmesi hastalığın önlenmesi, ilerleyişin durdurulması, sürecin öngörülmesi ve etkili tedavi yaklaşımlarının geliştirilmesi açııından önem taşımaktadır (9). Genetik belirleyiciler olarak hastalıkla ilişkili HLA allellerinin ortaya konulması yoğun ilgiye neden olmaktadır.

T1DM ile ilişkili pek çok çalışma HLA sınıf ॥ DR-DQ tiplerine odaklanmıştır. Sınıf I HLA-A, B, C alleleri ile ilgili daha az sayıda çalışma bulunmaktadır (10-11). T1DM'li Türk çocukları ile sınıf II HLA DR ve DQ arasındaki birlikteliğe ilişkin oldukça az sayıda çalışma bulunmaktadır. Dahası; sınıf I HLA A,B ve C grupları ile günümüze kadar yapıımış çalışma bulunmamaktadır. Bölgemiz Suriyeli göçmen ve çevre illerden gelen çocuklar nedeni ile genetik çeşitliliğin yoğun olduğu bir bölgedir. Bu çalışma bu iki açıdan bölgesel verilerin derlenmesine odaklanmıştır.

\section{GEREÇ ve YÖNTEM}

Çalışma 2016 Mart-2019 Mayıs arası T1DM tanısı ile izlenen yaşları 1-18 yaş arası 98 hasta ile 80 sağlıklı çocuk katıldığı tek merkezli bir araştırmadır. Çalışma için Klinik Araştırmalar Etik Kurulu'ndan onay alındı. Olgulara T1DM tanısı aşağıdaki kriterlere göre konuldu: poliüri ve /veya polidipsi öyküsü, 200 mg / dL'nin üzerindeki kan glikozu, düșük insülin ve C-peptid seviyesi, glikolize hemoglobin A1C'nin (HbA1C) yüksekliği (\% 6.5 üzeri) ve insülin gereksinimi. Yeni tanı almıș T1DM hastalarından Glutamik asit dekarboksilaz (GAD), adacık hücresi (ICA) ve insülin (IAA) otoantikorları,HLA-DR-HLA-DQ, HLA-A,B,C bölgesinin moleküler analizleri için kan alındı. Sağlıklı çocuklarda sınıf I HLA-A, B, C için test uygulanamadı. Dışlama ölçütleri Tip 2 diyabet, MODY (Maturity Onset Diabetes of Young), eşlik eden sistemik ve otoimmün hastallklar olarak belirlendi. Tarama sonucunda MODY tanısı alan 8, eşlik eden çölyak hastalığı bulunan 4, Hashimoto saptanan 6 olgu çalışmaya dâhil edilmedi. Kontrol grubu sorgulama ile anne-baba ve kardeşleri ile kendilerinde bilinen sistemik-kronik hastalığı olmayan yaşları 5-18 yaş arası çocuklar arasından seçildi.

\section{HLA genotiplendirmesi}

HLA genetik analizleri PCR yöntemi ile çalışıldı. DNA ekstraksiyonu, asit guanidinyum tiyosiyanat-fenol-kloroform ekstraksiyonu ile tek aşamalı RNA izolasyon metoduna göre yapıldı. DNA kalitesi ve konsantrasyonları belirlendi. HLA sınıf II genotipleme PCR-bazlı olarak yapıldı. DNA amplifikasyonu ișlemi, üretici firmanın yönergelerine göre uygulandı

\section{İstatistik}

HLA haplotip frekansları, doğrudan gen sayımı ile hesaplandı. T1DM ve sağlıklı çocuklar arasındaki HLA haplotip dağıımlarındaki statik fark, Yates'in düzeltmesi (two-tailed) ile yapılan Ki-kare testi $\left(\mathrm{X}^{2}\right)$ testi kullanılarak belirlendi. Odds ratio (OR) ve\% 95 güven aralı̆ı, HLA DRB1 ve DQB1 alelleri ve haplotipinin duyarllık etkisini değerlendirmek için Woolf formülü kullanılarak hesaplandı. $\mathrm{P}<0.05$ değeri istatistiksel olarak anlamlı kabul edildi. İstatistiksel analiz, Windows için SPSS 22.1 (SPSS, Chicago, IL) kullanılarak yapıldı.

\section{BULGULAR}

Hastaların 45 (\%44.1) kı, 53'ü (\%55.9) erkekti. T1DM'li çocukların tanı yaş ortalamaları $11.23 \pm 3.21$ olarak saptandı. Yeni tanılı T1DM'li çocuklarda tanı anındaki klinik ve laboratuar özellikler Tablo I'de verilmiștir. Sağlıklı çocukların $(n=80) 41^{\prime} \mathrm{i}$ (\%51.2) kIz, 39'u (\%48.8) erkekti. Yeni tanilı T1DM'lilerin 15'i (\%15.3) Suriyeli göçmen, 19'u (\%19.4) ise çevre illerden gelen çocuklardan oluşmaktaydı. T1DM'li olgularda HLA sınıf I ve II allel gruplarının dağllımı Tablo II'de verilmiştir. HLA sınıf I ve II gruplarından en sık saptanan lokuslar ve oranları DQ2 60 (\%61.2), DR3 48 (\%49), A2 36(\%36.8), DQ3 34 (\%34.7), A3 
Tablo I: Yeni tanılı T1DM’li olguların tanıdaki klinik özellikleri.

\begin{tabular}{|c|c|c|c|}
\hline & \multicolumn{3}{|c|}{ T1DM (n=98) } \\
\hline & Kız & Erkek & Toplam \\
\hline n/(\%) & $45 /(\% 44.1)$ & $53 /(\% 55.9)$ & $98 /(\% 100)$ \\
\hline Tanı yaşı (ort_SD) & $12.64 \pm 4.24$ & $12.37 \pm 3.78$ & $12.50 \pm 3.65$ \\
\hline HbA1C (ort $\pm S D)$ & $11.05 \pm 5.67$ & $11.23 \pm 2.32$ & $11.01 \pm 3.33$ \\
\hline C-peptid (ng/ml) & $0.41 \pm 1.34$ & $0.45 \pm 0.95$ & $0.42 \pm 0.78$ \\
\hline İnsülin ( $\mu \mathrm{IU} / \mathrm{ml})$ & $3.26 \pm 4.54$ & $2.98 \pm 3.12$ & $3.01 \pm 3.16$ \\
\hline Anti-GAD pozitif (n) & 35 & 44 & 79 \\
\hline Anti-ICA pozitif (n) & 36 & 38 & 74 \\
\hline Anti-IA pozitif (n) & 32 & 37 & 69 \\
\hline
\end{tabular}

GAD: glutamik asit dekorboksilaz, ICA: islet cell antibody, IA: insulin antibody

Tablo II: T1DM'li olgularda sınıf | ve || HLA lokuslarının dağlımı.

\begin{tabular}{|c|c|c|c|c|c|c|c|c|c|c|c|c|c|c|}
\hline \multicolumn{9}{|c|}{ SINIF I } & \multicolumn{6}{|c|}{ SINIF II } \\
\hline \multicolumn{3}{|c|}{ HLA-A } & \multicolumn{3}{|c|}{ HLA-B } & \multicolumn{3}{|c|}{ HLA-C } & \multicolumn{3}{|c|}{ DQ } & \multicolumn{3}{|c|}{ DR } \\
\hline Lokus & $\mathrm{n}$ & $\%$ & Lokus & $\mathrm{n}$ & $\%$ & Lokus & $\mathbf{n}$ & $\%$ & Lokus & $\mathbf{n}$ & $\%$ & Lokus & $\mathbf{n}$ & $\%$ \\
\hline $\mathrm{A} 1$ & 14 & 14.2 & B7 & 6 & 6.1 & $\mathrm{C} 1$ & 5 & 5.1 & DQ2 & 60 & 61.2 & DR1 & 10 & 10.26 \\
\hline $\mathrm{A} 2$ & 36 & 36.8 & B8 & 18 & 18.1 & $\mathrm{C} 2$ & 4 & 4.05 & DQ3 & 34 & 34.7 & DR3 & 48 & 49 \\
\hline $\mathrm{A} 3$ & 26 & 26.6 & B13 & 7 & 7.1 & C3 & 13 & 13.2 & DQ5 & 3 & 3.06 & DR4 & 25 & 25.5 \\
\hline A11 & 5 & 5.2 & B14 & 3 & 3.1 & C4 & 20 & 20.4 & DQ6 & 1 & 1.02 & DR7 & 4 & 4.08 \\
\hline A23 & 1 & 1.02 & B15 & 9 & 9.2 & C5 & 3 & 3.06 & & & & DR9 & 1 & 1.02 \\
\hline A24 & 8 & 8.1 & B18 & 7 & 7.1 & C6 & 12 & 12.4 & & & & DR10 & 2 & 2.04 \\
\hline A26 & 3 & 3.02 & B27 & 2 & 2 & $\mathrm{C} 7$ & 25 & 25.5 & & & & DR11 & 7 & 7.14 \\
\hline A29 & 2 & 2.02 & B35 & 15 & 15.2 & C8 & 1 & 1.02 & & & & DR15 & 1 & 1.02 \\
\hline $\mathrm{A} 30$ & 2 & 2.04 & B37 & 1 & 1 & C12 & 6 & 6.1 & & & & & & \\
\hline \multirow[t]{10}{*}{ A33 } & 1 & 1.02 & B38 & 2 & 2 & C14 & 2 & 2.04 & & & & & & \\
\hline & & & B39 & 1 & 1 & C15 & 3 & 3.06 & & & & & & \\
\hline & & & B40 & 6 & 6.1 & $\mathrm{C} 16$ & 3 & 3.06 & & & & & & \\
\hline & & & B41 & 4 & 4.1 & C49 & 1 & 1.02 & & & & & & \\
\hline & & & B44 & 10 & 10 & & & & & & & & & \\
\hline & & & B45 & 1 & 1 & & & & & & & & & \\
\hline & & & B51 & 3 & 3.1 & & & & & & & & & \\
\hline & & & B52 & 1 & 1 & & & & & & & & & \\
\hline & & & B53 & 1 & 1 & & & & & & & & & \\
\hline & & & B55 & 1 & 1 & & & & & & & & & \\
\hline
\end{tabular}

26 (\%26.6) olarak saptandı (Tablo II). En sık saptanan allel sıklğı Suriyeli göçmen ve çevre illerden gelen çocuklarda çalışma grubu ile benzerdi. (Suriyeli çocuklarda DQ2 9 (\%60), DR3 6 (\%40) iken çevre illerden gelen çocuklarda DQ2 11(\%57.8), DR3 8 (\%42) olarak saptandı). Sınıf I HLA-A,B,C lokusları Şekil1, allel dağlımı ise Tablo Il'te verilmiştir. Bu lokuslarda en sık saptanan allel dağıımı ve oranları ise HLA-A*02:03, HLA-A*02:24 ve
HLA-A*03:03\%9.18 (her üçü için), HLA-B*08:08, HLA-B*08:35 \%3.6 ve HLA-B*35:35 \%4.08, HLA-C*04:07 \%6.12, HLA-C*07:07 \%6.12 ve HLA-C*07:16 \%9.18 olarak saptandı. Sınıf II HLA DQ ve DR lokusları Şekil 2, allel dağılımı ise Tablo III'de verilmiştir. Bu lokuslarda en sık saptanan allel dağlımı ve oranları HLAB1-DQ*02:03 41 (\%42), HLAB1-DR*03:04 33 (\%33.6), HLAB1-DQ*03:03 20 (\%20.1)'di. En sık saptanan allel 


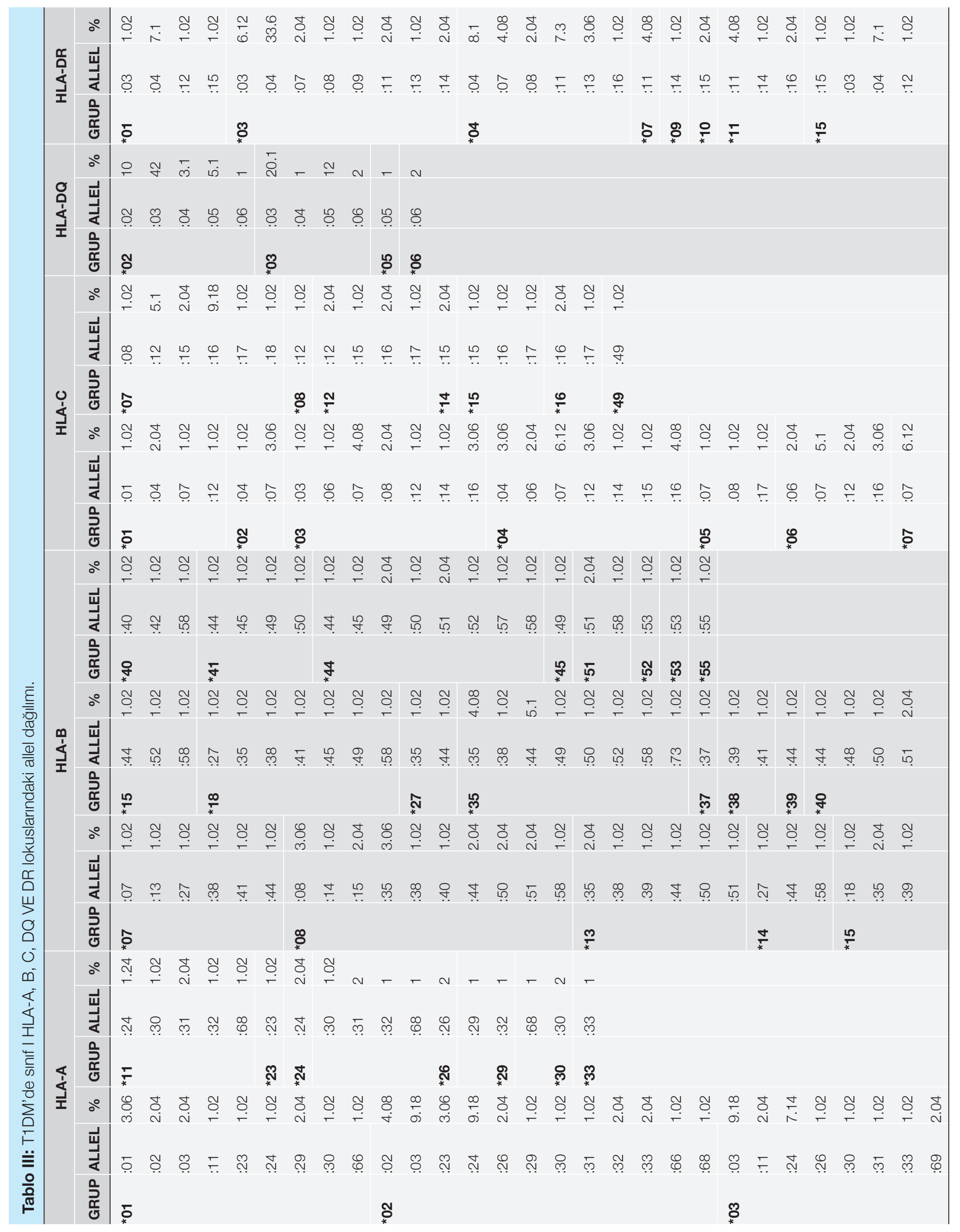


Tablo IV: T1DM'li ve sağlıklı çocuklarda HLA DR ve DQ antijenlerinin Odds ratio ve $p$ değerleri.

\begin{tabular}{|c|c|c|c|c|c|c|}
\hline & HLA & T1DM (n) & Sağlıkı (n) & Odds ratio( $95 \% \mathrm{Cl}$ ) & $\mathbf{x}^{2}$ & $\mathbf{p}$ \\
\hline \multirow{4}{*}{$\mathbf{D Q}$} & DQ2 & 60 & 14 & $7.44(3.67-15.07)$ & 34.66 & $<0.001$ \\
\hline & DQ3 & 34 & 49 & $0.33(0.18-0.62)$ & 12.48 & $<0.001$ \\
\hline & DQ5 & 3 & 8 & $0.28(0.72-1.09)$ & 3.65 & 0.06 \\
\hline & DQ6 & 1 & 9 & $0.08(0.001-0.065)$ & 8.69 & 0.01 \\
\hline \multirow{8}{*}{ DR } & DR1 & 10 & 12 & $0.64(0.26-1.57)$ & 0.93 & 0.46 \\
\hline & DR3 & 48 & 11 & $6.02(2.82-12.74)$ & 24.66 & $<0.001$ \\
\hline & DR4 & 25 & 16 & $1.36(0.79-2.79)$ & 0.75 & 0.388 \\
\hline & DR7 & 4 & 2 & $1.65(0.29-9.30)$ & 0.33 & 0.564 \\
\hline & DR9 & 1 & 3 & $0.26(0.02-2.56)$ & 1.49 & 0.257 \\
\hline & DR10 & 2 & 2 & $0.81(0.11-5.90)$ & 0.04 & 0.362 \\
\hline & DR11 & 7 & 17 & $0.28(0.11-0.71)$ & 7.51 & 0.008 \\
\hline & DR15 & 1 & 1 & $0.81(0.05-13.229$ & 0.02 & 0.885 \\
\hline \multirow{7}{*}{$\begin{array}{l}\text { DR-DQ } \\
\text { haplotipleri }\end{array}$} & DR3 ve/veya DR4 & 73 & 27 & $5.73(2.99-10.76)$ & 29.69 & $<0.001$ \\
\hline & DRB $1{ }^{*} 03-\mathrm{DQB} 1{ }^{*} 02$ & 48 & 6 & $11.84(4.71-29.75)$ & 35.85 & $<0.001$ \\
\hline & $\mathrm{DRB} 1{ }^{*} 01-\mathrm{DQB} 1{ }^{*} 05$ & 11 & 1 & $9.98(1.26-79.13)$ & 6.96 & 0.002 \\
\hline & $\mathrm{DRB} 1{ }^{*} 01-\mathrm{DQB} 1{ }^{*} 02$ & 3 & 2 & $1.21(0.19-7.47)$ & 0.05 & 0.830 \\
\hline & DRB $1{ }^{*} 03-\mathrm{DQB} 1{ }^{*} 03$ & 1 & 4 & $0.086(0.004-1.62)$ & 2.55 & 0.102 \\
\hline & $\mathrm{DRB} 1{ }^{*} 04-\mathrm{DQB} 1{ }^{*} 02$ & 6 & 1 & $5.15(0.60-43.71)$ & 2.72 & 0.132 \\
\hline & $\mathrm{DRB} 1{ }^{*} 04-\mathrm{DQB} 1{ }^{*} 03$ & 19 & 13 & $1.23(0.56-2.69)$ & 0.29 & 0.588 \\
\hline $\begin{array}{l}\text { DR3 ve DR4 } \\
\text { dişı haplotipler }\end{array}$ & $x / x$ & 25 & 57 & $0.16(0.08-0.31)$ & 38.08 & $<0.001$ \\
\hline
\end{tabular}

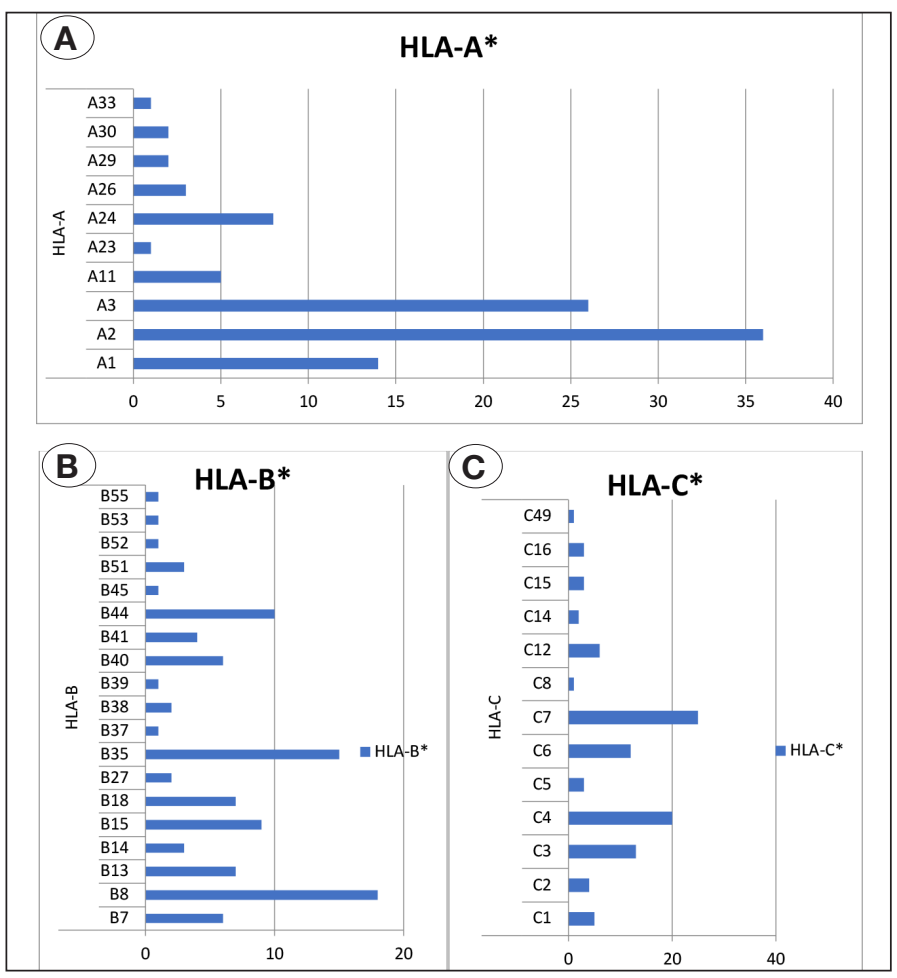

Şekil 1: T1DM'li çocuklarda sınıf | HLA-A/B/C lokus dağllıımı. A) T1DM'de HLA-A lokus dağılımı, B) T1DM'de HLA-B lokus dağılımı, C) T1DM'de HLA-C lokus dağlımı

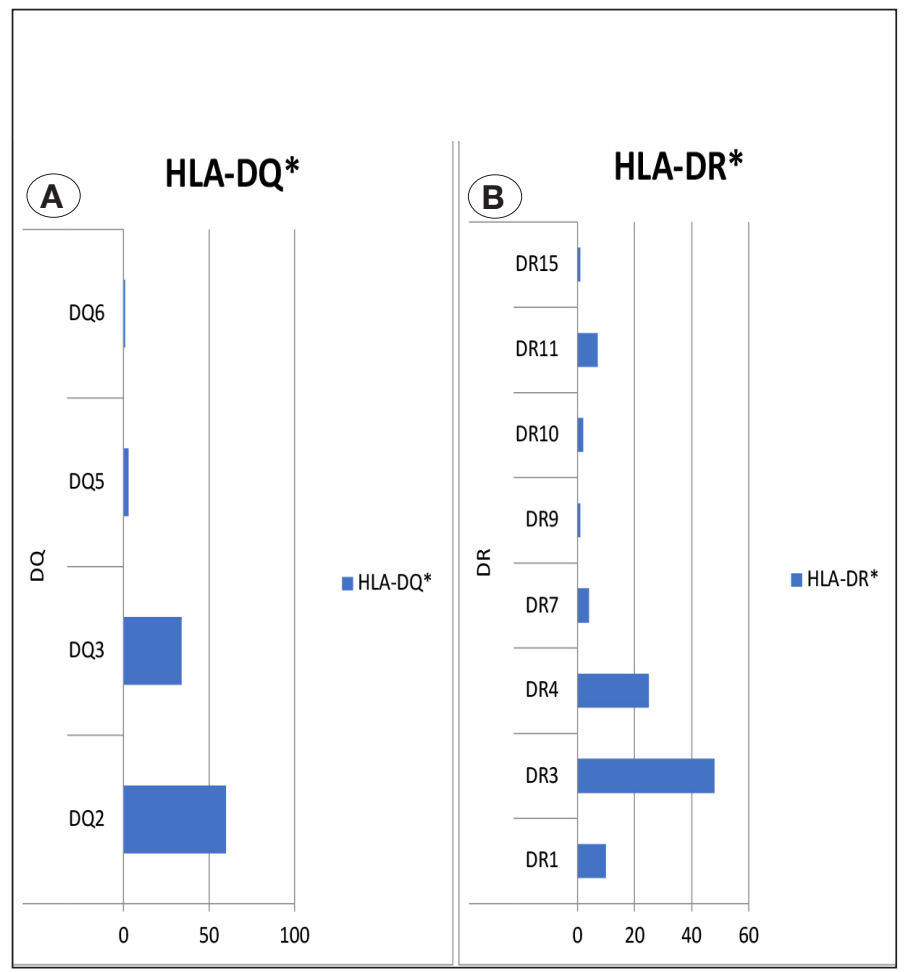

Şekil 2: T1DM'li çocuklarda sınıf II HLA-DQ ve DR dağlıımı. A) T1DM'de HLA-DQ dağılımı, B) T1DM'de HLA-DR dağıımı 


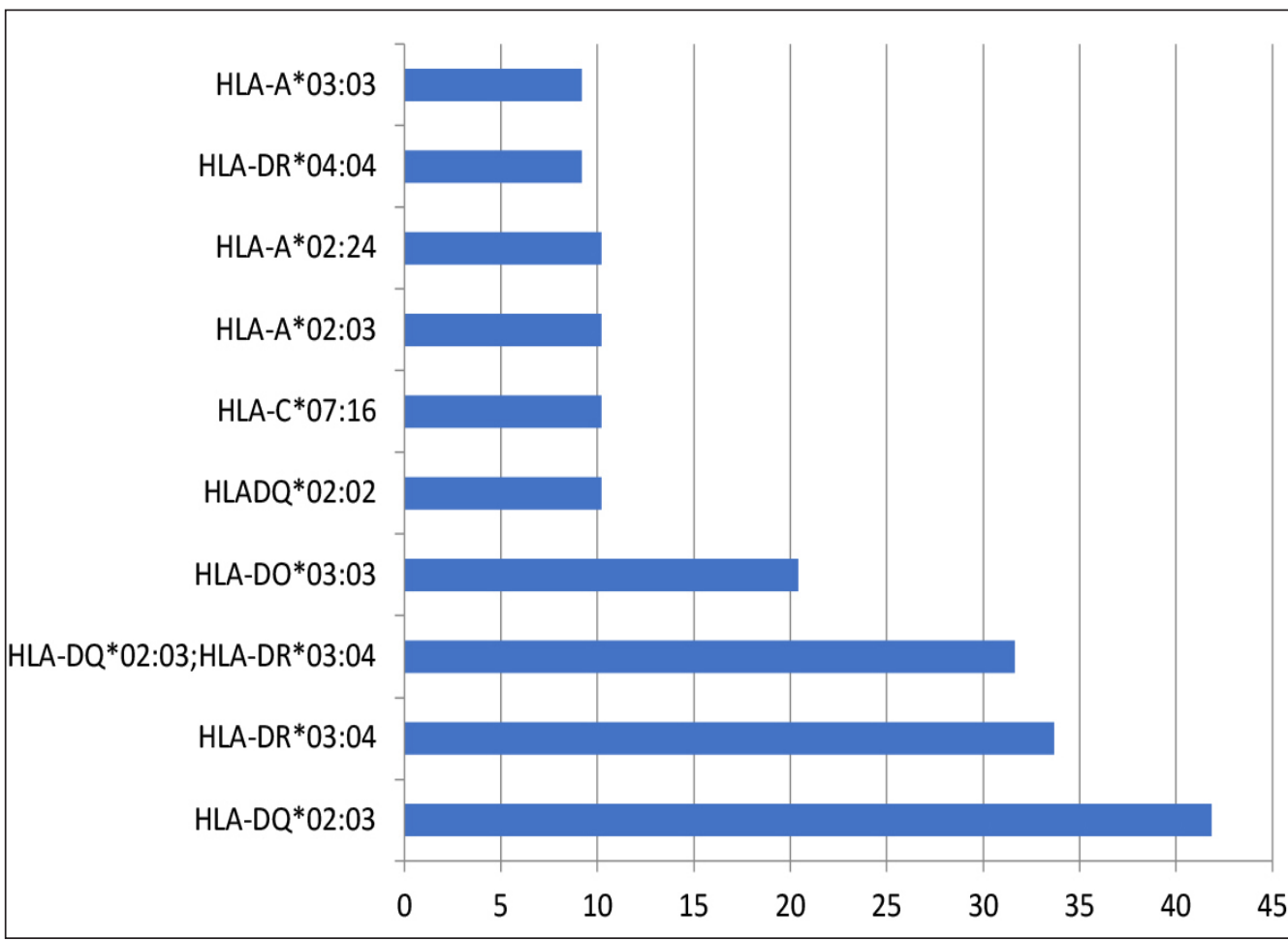

Şekil 3: T1DM'de en sık görülen HLA allel ve haplotiplerin dağılımı.

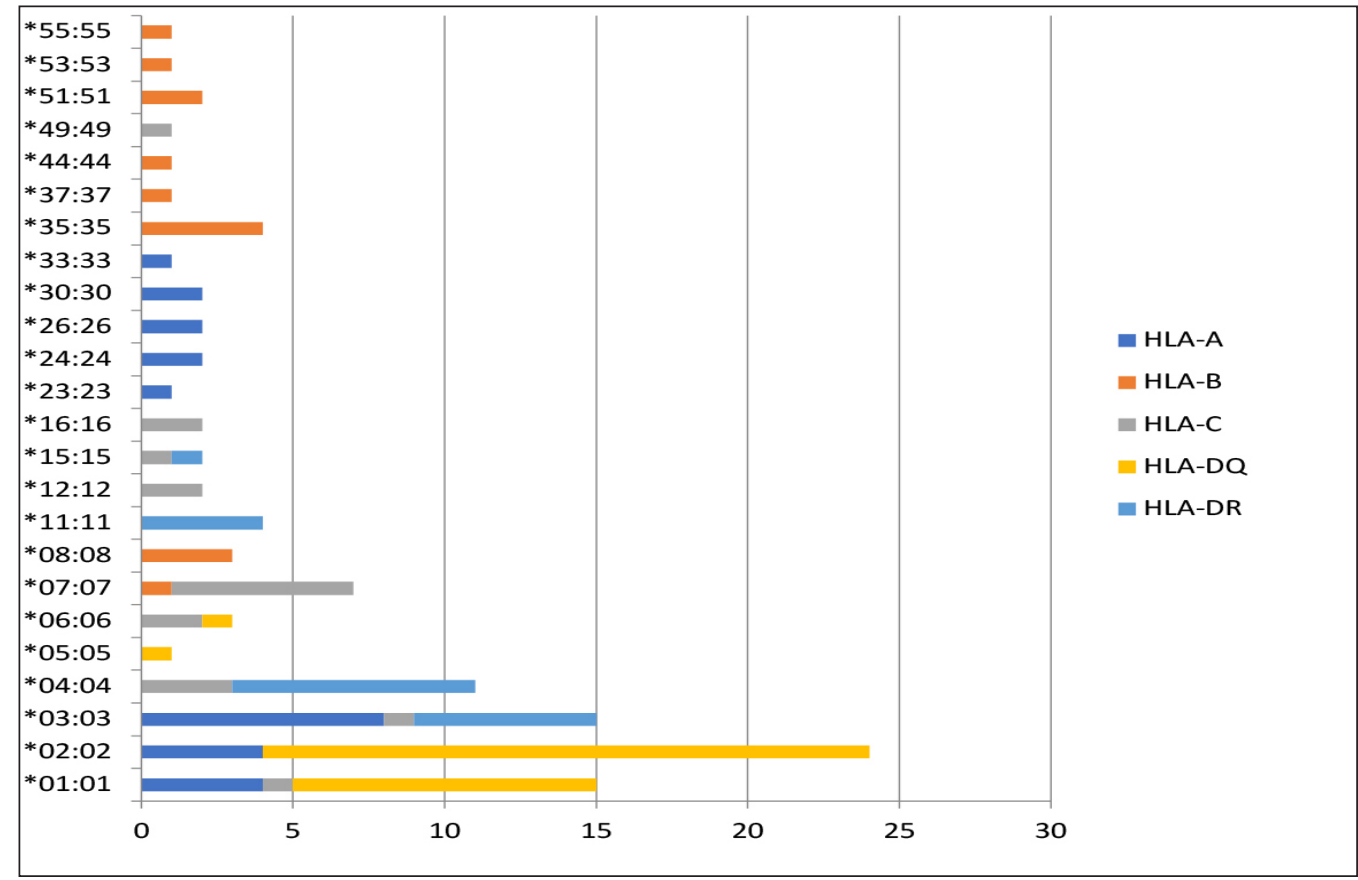

Şekil 4: T1DM'de HLA gruplarına göre en sık görülen homozigot allel dağılımı.

ve haplotipler Şekil 3'te gösterilmiştir. T1DM'de heterozigot allel sıklığı homozigotlardan daha sık bulundu. HLA gruplarındaki homozigot allel dağılımı Şekil 4'te verilmiştir. En sık homozigot allel dağılımı HLA DQ (HLA-DQ*02:02) grubunda saptandı.

T1DM için riskli HLA sınıf I DR ve DQ allel gruplarının belirlenmesi için kontrol grubu ile karşılaştırıldığında en riskli allel ve haplotip grupları DQ2 $(\mathrm{OR}=7.44)$, DR3 $(\mathrm{OR}=6.02)$, DRB1*03-DQB1*02
$(\mathrm{OR}=11.84), \quad \mathrm{DRB} 1{ }^{*} 01-\mathrm{DQB} 1{ }^{*} 05 \quad(\mathrm{OR}=9.98), \quad \mathrm{DRB} 1{ }^{*} 04-$ $\mathrm{DQB} 1{ }^{*} 02(\mathrm{OR}=5.15)$ olarak bulunmuştur (Tablo IV). HLA DR3/4 dışı toplam haplotiplerin sayısı T1DM'li çocuklarda 25, kontrol grubunda ise 57 olarak bulundu. $\left(X^{2}=38.08\right) \quad(O R=0.16)$. DQ6ve DR11 (OR= 0.28), HLA lokus bölgeleri kontrol grubuna göre daha az sıklıkta olduğu saptandı (sırası ile $\mathrm{OR}=0.08$ ve $0.28 ; p=0.01$ ve $p=0.008$ ). 


\section{TARTIŞMA}

T1DM, genetik ve çevresel koşulların belirlediği otoimmün bir hastalıktır. Genetik temel çoğunlukla bazı HLA gruplarının varlığında T1DM için artmış bir risk ile açıklanmaktadır (12). T1DM ve HLA ilişkisi çok çalışılmış ancak günümüze kadar bütünüyle aydınlatılamamıştır (13). Sınıf II HLA allel ve haplotipleri çalışmaların odağı olmakla beraber sınıf I HLA grupları ile T1DM arasında ilişki varlığını bildiren çalışmalar rapor edilmektedir (14). T1DM'ye duyarlıı̆̆ı artıran HLA çeşitliliği ırk etnik köken ve bölgeden bölgeye farkllık göstermektedir (15). Bildiğimiz kadarı ile T1DM tanılı Türk çocukları ile HLA gen bölgeleri arasındaki ilişkiyi araştıran az sayıda çalışma bulunmaktadır $(16,17)$. Çalışmanın öne çıkan önemli yanlarından birisi T1DM riskinin artışı ile ilişkili HLA sınıf ॥| genotiplendirmesine ilişkin bölgeselverileri ortaya çıarmak iken diğeri HLA sınıf I allel sıklığına ilişkin ülkemiz ve bölgemize ait ilk rapor olmasıdır.

Çalışmamızda DQ2 ve DR3 T1DM için en riskli HLA bölgeleri olarak bulunmuştur. Bu lokustaki HLAB1-DQ*02:03 en sik allel olarak saptanmıştır. DR3 ikinci en riskli HLA bölgesi olarak saptandı bu bölgedeki HLAB1-DR*03:04 alleli ikinci en sık allel olarak bulundu. Çoğu çalıșmada bölgeden bölgeye değişen riskli HLA alleller bildirilmektedir $(8,10,15)$. T1DM için bölgemiz için bulgumuz riskli allel çeşitliliği genel olarak literatür ile uyumlu gözükmektedir. Keskin ve ark.(17) bölgemizde yaptığı önceki çalışmada en riskli HLA bölgesi olarak DR3 rapor edilmişti.

Çalışmamızda DRB1*03-DQB1 ${ }^{*} 02$, en riskli haplotip olarak saptanmıştır. Bu bulgu genel literatür verileri ile ve bölgemizde önceden yapılan çalışma ile aynı bulunmuştur $(8,10,15,17)$. En riskli diğer iki haplotipler DRB1*01-DQB1*05 ve DRB1*04DQB1*02 olarak saptandı. Bu bulgular T1DM için en duyarlı haplotipler olarak bildirilen DR/DQ kombinasyonun bölgemiz için de geçerli olduğunu ortaya koymuştur.

Bu çalışma DQ6 ve DR11 HLA bölgelerinin daha az sıklıta olduğu saptanmıştır. T1DM için koruyucu olan bu bölgeler Keskin ve ark. (17) sonuçları ile karşılaştııılığında DR11'in onlarınki ile aynı DQ6'nın ise farklı olduğu görülmektedir. T1DM için duyarllığı azaltan HLA gen bölgeleri için değişken allel çeşitliliği bulunmaktadır (18). Keskin ve ark. (17) 2012'de bölgemizde yaptığı çalışma ile çalışmamız arasında HLA dağlım oranları arasında bazı farklar bulunmaktadır. Geçen süre boyunca ortaya çıkan bu değişimleri bölgemizin değişen demografik nüfus yapısından kaynaklandığını düşünmekteyiz. Merkezimiz etnik çeşitliliğin yüksek olduğu çevre illerden ve Suriye'den gelen göçmenlerin kabul edildiği yoğun bir merkezdir. DQ2 ve DR3 arasındaki dağılım sıklığı açısından görülen yer değiştirmeye Suriyeli ve çevre illerden gelen çocuklardaki DQ2 oranının daha yüksek olması katkı sağlamış görünmektedir. Benzer şekilde; önceki çalışmaya göre DQ6 sıklğında azalma yönünde görülen değişim de demografik yapıdaki değişimden kaynaklanıyor görülmektedir (Suriyeli çocuklarda DQ6 saptanmazken çevre illerden gelen çocukların sadece 1'inde (\%5.1) DQ6 bulundu).

Çalışmamızda T1DM için duyarlı olan heterozigot haplotiplerin homozigotlardan daha sık saptanmıştır. En sık saptanan
DQ*02:02 homozigot haplotipidi. Önceki çalısmalarda da benzer olarak heterozigositenin T1DM için daha fazla risk oluşturduğu bildirilmektedir (19).

Çalışmamızda sınıf I HLA-A, B, C gen bölgelerine ilişkin sadece hastalardaki dağılım da incelenmiştir. Çallşmamız Türk çocuklarında T1DM ve sınıf I HLA gen bölgeleri arasındaki birlikteliği bildiren ilk rapordur. En sık saptanan lokuslar HLA-A için A2 36(\%36.8) ve A3 26 (\%26.6), HLA-B için B8 18 (\%18.1), B35 15 (\%15.2) iken HLA-C için C7 25 (\%25.5), C4 20 (\%20.4) olarak saptanmışıı. HLA-A, B, C allelleri sağlıklı populasyonlarda sık görülen alt tipler olmakla beraber T1DM için bulduğumuz oranlar Türk toplumu için yapılan önceki bir çalışmadaki kontrol grubunun sonuçları ile karşılaştııldığında yüksek gözükmektedir (20). Bu çalışmada HLA-A2 için allel sıklığı \%22.5 iken bizim çalışmamızda \%36.8, olarak bulunmuştur. Yine bu çalsşmada HLA-A3 için ise \%11.3, HLA B8 için \% 4.3 olarak rapor edilirken çalıșmamızda bu oranlar \%26.6 ve \%18.1 olarak saptanmıştır. Bulgularımız HLA sınıf I için de bazı allel gruplarının T1DM için artmış bir risk taşıyor olabileceğini düşündürtmektedir.

Sonuç olarak; bu çalışmada T1DM için en riskli HLA allel grupları ve haplotipleri olarak DR3-DQ2 ve DRB1 ${ }^{\star} 03-\mathrm{DQB} 1{ }^{*} 02$, DRB $1{ }^{*} 04-\mathrm{DQB} 1{ }^{*} 03, \mathrm{DRB} 1{ }^{*} 01-\mathrm{DQB} 1{ }^{*} 05$ bulunurken HLA-A2/ A3, HLA-C7/C4 ve HLA B8/35 allel grupların sıklığında yüksek bir sıklık saptanmıştır. Bu bulgular, T1DM tanılı Türk çocuklarında HLA sınıf II HLA DR3-DQ2 allel gruplarındaki artmış sıklık olduğunu ve T1DM ile bazı allellerinin artmış sıklığı nedeni ile HLA I sınıfı gen bölgeleri arasındaki ilişkinin de araştıııması gerektiğine işaret etmektedir.

\section{KAYNAKLAR}

1. Morahan G, Varney M. The genetics of type 1 diabetes. In The HLA Complex in Biology and Medicine: A Resource Book. Mehra NK, Ed., New Delhi, Jay Pee Brothers Publishing 2010;205-18.

2. Cucca F, Muntoni F, Lampis R, Frau F, Argiolas L, Silvetti M, et al. Combinations of specific DRB1, DQA1, and DQB1 haplotypes are associated with insulin-dependent diabetes mellitus in Sardinia. Hum Immunol 1993;7:85-94.

3. Noble JA, Valdes AM, Cook M, Klitz W, Thomson G, Erlich HA. The role of HLA class II genes in insulin-dependent diabetes mellitus: molecular analysis of 180 Caucasian, multiplex families. Am J Hum Genet 1996;59:1134-48.

4. Dorman JS1, Bunker CH. HLA-DQ locus of the human leukocyte antigen complex and type 1 diabetes mellitus: a HuGE review. Epidemiol Rev 2000;22:218-27.

5. Atkinson MA, Eisenbarth GS. Type 1 diabetes: new perspectives on disease pathogenesis and treatment. Lancet 2001;358:221-9.

6. Noble JA, Valdes AM. Genetics of the HLA region in the prediction of type 1 diabetes. Curr Diab Rep 2011;11:533-42.

7. Erlich H, Valdes AM, Noble J, Carlson JA, Varney M, Concannon P, Mychaleckyj JC, et al. HLA DR-DQ haplotypes and genotypes and type 1 diabetes risk: analysis of the type 1 diabetes genetics consortium families. Diabetes 2008;57:1084-92.

8. Noble JA, Valdes AM. Genetics of the HLA Region in the Prediction of Type 1 Diabetes. Curr Diab Rep 2011;11:533-42. 
9. Michels A, Zhang L, Khadra A, Kushner JA, Redondo MJ, Pietropaolo M. Prediction and prevention of type 1 diabetes: update on success of prediction and struggles at prevention. Pediatr Diabetes 2015;16:465-84.

10. Noble JA, Valdes AM, Varney MD, Carlson JA, Moonsamy P, Fear AL, et al. HLA class I and genetic susceptibility to type 1 diabetes: results from the Type 1 Diabetes Genetics Consortium. Diabetes 2010;59:2972-9.

11. Barker JM, Triolo TM, Aly TA, Baschal EE, Babu SR, Kretowski A, et al. Two single nucleotide polymorphisms identify the highestrisk diabetes HLA genotype: potential for rapid screening. Diabetes 2008;57:3152-5.

12. Janelle A. Noble and Henry A. Erlich. Genetics of Type 1 Diabetes. Cold Spring Harb Perspect Med 2012;2:a007732.

13. Valdes AM, Noble JA, Génin E, Clerget-Darpoux F, Erlich HA, Thomson G. Modeling of HLA class II susceptibility to type 1 diabetes reveals an effect associated with DPB1. Genet Epidemiol 2001;21:212-3.

14. Noble JA, Valdes AM, Bugawan TL, Apple RJ, Thomson G, Erlich HA. The HLA class I A locus affects susceptibility to type 1 diabetes. Hum Immunol 2002;63:657-664
15. Noble JA. Immunogenetics of type 1 diabetes: A comprehensive review. J Autoimmun 2015;64:101-12.

16. Ozsahin H, Haktan M, Ozbakir F, Aydin A, Yazici H. The type 1 diabetes and HLA-DR in Turkey. Diabete Metab 1991;17:421-3.

17. Mehmet Keskin, Ayşe Aygün, Sacide Pehlivan, Özlem Keskin, Kor Y, Balat A, et al. Trends in the Frequency of HLA DR-DQ Haplotypes Among Children and Adolescents with Type 1 Diabetes Mellitus in the Southeast Region of Turkey. J Clin Res Pediatr Endocrinol 2012;4:189-92.

18. Wu YL, Ding YP, Gao J, Tanaka Y, Zhang W. Risk factors and primary prevention trials for type 1 diabetes. Int J Biol Sci 2013;9:666-79.

19. Nguyen C, Varney MD, Harrison LC, Morahan G. Definition of highrisk type 1 diabetes HLA-DR and HLA-DQ types using only three single nucleotide polymorphisms. Diabetes 2013;62:2135-40.

20. Mustafa Soyöz, Burcu Akman, İsmail Totur, Sinem Topçu, Özkızılcık Koçyiğit A, et al. Human Leukocyte Antigen Class I-II Allele Frequencies and Association Between Human Leukocyte Antigen Alleles and ABO Blood Group Antigens. Turk J Immunol 2016;4:14-8. 